\title{
A política externa brasileira e a "circunstância democrática": do silêncio respeitoso à politização ruidosa
}

\author{
Brazilian foreign policy and the "democratic circumstance": \\ from respectful silence to noisy politicization
}

DAWISSON BELÉM LOPES*

Rev. Bras. Polít. Int. 54 (1): 67-86 [2011]

"A política não é um problema de episteme, mas de doxa."

(CASTORIADIS, 2004, 212)

\section{Introdução}

Os anos 1990 iniciaram-se com Fernando Collor de Mello a ocupar a presidência do Brasil. Sua posse coroou um processo de abertura escalonada do regime político à participação popular, com realização de eleições diretas para o governo federal em 1989 e uma acirrada disputa, em dois turnos, envolvendo o próprio Collor de Mello e o adversário Luiz Inácio Lula da Silva.

A presidência de Collor de Mello foi marcada por sobressaltos, principalmente na esfera econômica. A inflação galopante da década anterior não foi controlada, e logo o arrojado plano econômico, elaborado pela ministra da Fazenda, Zélia Cardoso de Mello, fracassaria, minando a legitimidade de um governo que, ao longo de 2 anos e meio de duração, jamais pôde contar com apoio majoritário no Congresso Nacional. O processo de impedimento constitucional sepultou, em setembro de 1992, qualquer perspectiva de o primeiro presidente eleito pelo voto popular da Nova República chegar ao fim de seu mandato.

A tensão que marcou esse episódio da história republicana brasileira se justifica se o impeachment é tomado como o "batismo de fogo" das novas instituições democráticas do País. Afinal, o que hoje se alega é que, malgrado todo o transtorno político vivenciado à época, prevaleceu no Brasil o Estado de Direito, isto é, a saída constitucional, sem rupturas da ordem ou recurso a expedientes extralegais.

\footnotetext{
* Professor do Departamento de Relaçōes Internacionais da Pontifícia Universidade Católica de Minas Gerais (PUC Minas) e do Departamento de Ciências Jurídicas, Políticas e Gerenciais do Centro Universitário de Belo Horizonte (dawisson@gmail.com). O autor agradece os enriquecedores comentários feitos a versões prévias do texto por Antônio Jorge Ramalho da Rocha, Cesar Guimarães, Filipe Nasser, Marcelo Jasmin, Letícia Pinheiro, Luiz Feldman e Maria Regina Soares de Lima, bem como por pareceristas anônimos e pela editoria desta RBPI.
} 
Do ponto de vista da política externa conduzida pelo Ministério das Relaçōes Exteriores (MRE), já se registrava naquele período uma tentativa de "emplacar" uma nova imagem internacional do País quanto a temas de democracia e Estado de Direito. Tome-se, exemplificativamente, o discurso proferido pelo então ministro das Relações Exteriores, Celso Lafer, nas Nações Unidas, por ocasião da abertura da Assembleia Geral de 1992:

A democracia que hoje vivemos em toda sua plenitude no plano interno constitui garantia de estabilidade e coesão. Ensina-nos a conviver com as diferenças e as disparidades de uma sociedade plural. Permite-nos enfrentar crises e vicissitudes dentro da legalidade constitucional, ao mesmo tempo em que nos encoraja a defender seus princípios e métodos também no convívio com as demais Naçôes (LAFER apud SEIXAS CORRÊA, 2007, 553, ênfase acrescentada).

Para além da defesa da institucionalidade democrática, o ministro reforçou em seu discurso o compromisso brasileiro com o "espírito de civilidade" e, por conta disso, nossa natural credencial para participar da "reorganização do sistema internacional”. Em entrevista concedida após deixar o ministério, ele explicitou a racionalidade de sua fala:

$\mathrm{Na}$ tradição diplomática brasileira o discurso da ONU é importante, porque é um ponto de referência. Eu tinha, é claro, muita consciência disso. (...) Estávamos enfrentando uma grande crise dentro do estrito marco democrático, e qualquer que fosse o seu desfecho, sairíamos reforçados pela capacidade institucional de administrar um grande problema. Minha ida à ONU, a meu ver, tem essas duas dimensões: a da presença qualitativa do Brasil no mundo, que tentei marcar através do meu discurso, e a da gestão da crise como um elemento de reforço da legitimidade internacional do país, utilizável por quem viesse a me suceder (LAFER et al., 1993, 12).

Também é digna de registro a publicação, em 27 de agosto de 1992, de portaria que regulamentava o acesso público ao arquivo histórico do Itamaraty. Ela promoveu um importante avanço institucional, tanto no sentido de abertura da política externa brasileira (PEB) à avaliação contínua da sociedade quanto no de adequação do Itamaraty aos dispositivos constitucionais de 1988. O acesso ao arquivo sempre foi um grande problema para os pesquisadores - como salientou Pio Penna Filho (1999) -, os quais, em regra, "recorriam a fontes no exterior para escrever capítulos da história nacional” (p. 122). Lafer justificou, eventualmente, a medida tomada com uma apologia - temperada por ressalva - à democratização da política externa:

Sempre tive a conviç̧ão de que em uma democracia a transparência do poder é fundamental e de que o controle das políticas públicas pela cidadania deve 
ser feito através de uma informação apropriada. É claro que também sempre reconheci que há temas de segurança, temas mais delicados cuja divulgação envolve uma certa defasagem no tempo. Mas acho que não podemos ter documentos que não possam ser um certo dia acessados (LAFER et al., 1993, 11, ênfase acrescentada).

Com a queda de Collor, tomou posse o vice-presidente da República, Itamar Franco, ex-senador da República e opositor moderado ao regime dos militares (FAUSTO, 2002). No primeiro trimestre de 1993, sob a responsabilidade institucional do ministro Fernando Henrique Cardoso, realizou-se no Itamaraty um ciclo de seminários sobre os novos rumos a imprimir à política externa brasileira dali por diante. Dele participaram membros da sociedade com envolvimento nas questôes da PEB, nomeadamente: acadêmicos, empresários, sindicalistas e diplomatas (em atividade e aposentados). O ciclo, promovido pelo Instituto de Pesquisas de Relaçôes Internacionais (Ipri), chamado de "Reflexôes sobre a Política Externa Brasileira”, debateu, dentre outras questóes, o estatuto público da política externa, sua necessária democratização e os mecanismos concebíveis para tal.

Ao tratar do tema da transparência na gestão da PEB, o documento-síntese dos encontros assim expunha:

O Itamaraty pode escolher o que lhe interessa discutir publicamente, mas, pelos mais variados caminhos, a sociedade - setores da elite, pelo menos - também 'escolhem' os temas que querem discutir com os formuladores da política externa. A transparência é necessariamente uma via de mão dupla, e sujeita às flutuações e aos interesses a que Celso Lafer chama de 'agenda da opinião pública'. Constatou-se que é inevitável que alguns temas institucionais passem a fazer, em algumas circunstâncias, parte dessa agenda (MRE, 1993, 145, ênfases acrescentadas).

A abertura à sociedade dos antes opacos debates da PEB agora se apresenta como uma "inevitabilidade", no dizer dos participantes dos encontros. Dois aspectos do trecho reproduzido saltam aos olhos: a indisfarçada pretensão de tutela política itamaratyana ("o Itamaraty pode escolher o que lhe interessa discutir publicamente...") e a constatação de que existe uma agenda da opinião pública (ainda que essa "opinião pública" se restrinja a "setores da elite") da qual o MRE terá, circunstancialmente, de dar conta. A resignação, por parte do Itamaraty, ao debate público fica mais evidente na passagem seguinte:

No diálogo - que, em certa medida, já não é uma 'opção', mas uma necessidade imposta pela circunstância democrática -, se perdemos uma medida de liberdade', ganhamos com quem também tem formas de sensibilidade para as questôes internacionais e, sobretudo, reforçamos a legitimidade das posições diplomáticas brasileiras (idem, p. 145, ênfase acrescentada). 
$\mathrm{Na}$ subseção seguinte do documento em análise, intitulada "A necessidade da diplomacia pública”, encontram-se as primeiras propostas efetivas para maior capilarização social da PEB. O primeiro plano suscitado é a criação de um mecanismo institucionalizado de interlocução continuada entre os stakeholders da PEB, o qual assumiria as formas - complementares entre si - de: (i) uma espécie de grande conselho para exposição e debate das linhas gerais da PEB; (ii) foros de discussão mais restritos, em que se buscasse ouvir segmentos específicos da sociedade sobre áreas de interesse mais delimitadas (o exemplo, segundo o documento, seria o "Conselho Empresarial"); e (iii) articulação ad hoc mais intensa a respeito das medidas que o Estado brasileiro deveria tomar nas principais reuniōes internacionais. Essa aproximação da PEB com o público seria conduzida de forma descentralizada, pelas várias secretarias e subsecretarias dos ministérios e demais órgãos burocráticos do Estado brasileiro.

Como corolário dessas práticas, projetava-se que a diplomacia brasileira se tornasse uma "política nacional", com coordenação interna entre as burocracias do Estado nos três níveis federativos, o Congresso e algumas personalidades representativas da sociedade, e com a promoção do diálogo entre organizações políticas, empresariais, sindicais, culturais, acadêmicas etc. $\mathrm{O}$ documento autorreflexivo do Itamaraty prescrevia para "o problema da formulação de políticas" os seguintes remédios: (i) a introdução do componente internacional nos planos internos e (ii) a manutenção dos cenários internacionais atualizados, em suas múltiplas dimensóes (política, econômica, militar, estratégica) e seus múltiplos prazos (curto, médio e longo).

Ao fim do capítulo IV, porém, o documento concluía, de forma um tanto contraditória, com um apelo por maior incorporação da "dimensão nacional" à $\mathrm{PEB}$, não deixando de ressaltar, logo em sequência, que "a complexidade dos temas diplomáticos, frequentemente técnicos, pede processos constantes de formação dos funcionários, em que a dimensão geral e política das 'especializaçôes' seja sublinhada" (MRE, 1993, p. 160).

$\mathrm{Na}$ impossibilidade de o ex-governador do Distrito Federal, José Aparecido de Oliveira, assumir como chanceler, Itamar Franco trouxe para o comando interino do Ministério das Relaçóes Exteriores o diplomata de carreira Celso Amorim. A escolha provisória tornou-se a definitiva, e a dupla Franco e Amorim foi, com efeito, responsável pela condução da política externa do país entre julho de 1993 e dezembro de 1994.

O chanceler Amorim elaborou, em sua primeira passagem como chefe do Itamaraty, uma pequena coleção de discursos e artigos sobre a relação entre democracia e PEB. Em trecho de entrevista ao jornal Correio Braziliense, ainda em novembro de 1993, ele proferiu, não fugindo do tema:

O Brasil evoluiu na sua política interna, com democracia, maior transparência, maior respeito aos direitos humanos e a política externa atése atrasou um pouco, 
porque, digamos, em função de temores do passado, tínhamos uma atitude um pouco menos empenhada em relação a esses temas (AMORIM, 1995, 302, ênfase acrescentada).

$\mathrm{Na}$ fala de Amorim há o reconhecimento de certo descompasso entre o processo de democratização da política doméstica do país (caracterizado, dentre outros, pelo respeito aos direitos humanos, por uma maior transparência na gestão da coisa pública, pelo Estado de Direito) e a condução da política externa. A alegação era de que "temores do passado" (aqui, imaginamos, se esteja fazendo alusão à herança político-institucional da ditadura militar no Brasil) teriam impedido avanços mais robustos no rumo da democratização da PEB.

Mais adiante, em abril de 1994, Amorim voltaria a tratar publicamente do tema, em artigo publicado no mesmo Correio Braziliense, intitulado "Diplomacia e Democracia". À ocasião, de forma menos titubeante e lacônica, o diplomata reafirmou o compromisso do governo Franco com os pilares da democracia no exercício da PEB:

A ideia de que a diplomacia constitua atividade conspiratória, marcada pela intriga e pela dubiedade, é cada vez menos verdadeira. Por isso, a diplomacia brasileira, coerentemente com nossas aspirações democráticas, se caracteriza, por um lado, pela abertura ao diálogo participativo com a sociedade e, por outro, pela transparência com que perseguimos nossos objetivos em relação a outras nações. São estes atributos, que não se confundem com a ingenuidade ou a imprudência no trato dos assuntos de Estado, que garantem credibilidade à nossa ação externa (AMORIM, 1995, 243).

É curioso notar na passagem acima como Celso Amorim toma a cautela de justificar ao público a opção pela "abertura ao diálogo participativo com a sociedade", buscando desvencilhar-se da pecha de ingênuo ou imprudente como se aquele caminho por ele apontado não fosse o natural; como se a política externa não fosse uma política pública do Estado democrático brasileiro - ergo passível de reflexão social. A propósito, em suas formulaçóes sobre democracia e $\mathrm{PEB}$, Amorim não se limitou a pensar as conexões domésticas entre os conceitos. A articulação passava pela defesa obstinada de uma reforma do Conselho de Segurança das Nações Unidas que viesse a contemplar interesses brasileiros, sob o pretexto da "democratização das relações internacionais". Esses apelos apareceram com boa constância nos textos da época. Por exemplo, num balanço da gestão da PEB de Franco, preparado para o jornal Folha de S.Paulo, em que constava o seguinte parágrafo:

Nascido de um ato de afirmação cívica do regime democrático, o Governo Itamar Franco revigorou o compromisso de nossa diplomacia com a defesa e a promoção da democracia no interior dos Estados e no relacionamento entre 
eles. Trabalhamos intensamente em favor dos valores democráticos e do respeito aos direitos e às liberdades individuais, sempre em consonância com o princípio da não intervenção nos assuntos internos dos Estados (AMORIM, 1995, 17).

Maquiavel adotou a célebre metáfora da "roda da Fortuna" para significar que, por mais virtuoso que pudesse mostrar-se um governante, ele sempre estaria sujeito aos caprichos da sorte. No caso do Itamaraty, na primeira metade da década de 1990, aquele elemento "circunstancial" do pensamento maquiaveliano materializou-se com intensidade. Em decorrência, deu-se o despertar das ideias que associavam democracia e atividade diplomática e, além disso, atores pouco convencionais, com interesses envolvidos na formulação da política externa (os novos stakeholders do mundo pós-Guerra Fria), passaram a ser citados nas propostas de democratização dos processos decisórios, mesmo que por canais subdesenvolvidos ou incipientes. Cumpre, pois, reconhecer as mudanças significativas no discurso e, em menor medida, nas práticas da PEB do período.

\section{A busca da "virtude aristotélica"}

$\mathrm{Na}$ segunda metade dos anos 1990, sob a presidência do ex-chanceler e exministro da Fazenda do governo Itamar Franco, Fernando Henrique Cardoso, ocorrem transformações no arcabouço institucional para tratar as questôes internacionais do Brasil que aproximam, efetivamente, o processo de formulação da PEB de uma medida de poliarquia, com a abertura do debate político em outros níveis e a outros atores social e economicamente relevantes. Em 1997, por exemplo, é estabelecida a Assessoria de Relações Federativas (recriada, em 2003, como Assessoria Especial de Assuntos Federativos e Parlamentares), que acompanhava a possibilidade constitucional de incorporação de demandas dos governos subnacionais na composição do chamado "interesse nacional". Entre 1992 e 1999, foram criados o Comitê Empresarial Permanente do MRE, o Fórum Consultivo Social e Econômico do Mercosul, a Seção Nacional de Consulta sobre a União Europeia e o Grupo Interministerial de Trabalho sobre Comércio Internacional de Mercadorias e de Serviços (Gici), além de inúmeros conselhos empresariais bilaterais, o que adensou consideravelmente o relacionamento governo-empresariado no período. Em escrito de 1998, o embaixador Gelson Fonseca Jr. admitia:

Em nossa política interna, a democratização estimulou a ampliação do debate sobre temas diplomáticos, especialmente os que têm substância econômica. A agenda da opinião pública nem sempre coincide com as prioridades governamentais, mas exige uma atenção e cuidado permanentes (FONSECA JR., 1998, 366, ênfase acrescentada).

Pedro da Motta Veiga (2005), ao discorrer sobre a política externa comercial brasileira do período, convergiu com Fonseca naquela percepção: 
No campo das negociações comerciais, sua importância crescente na política comercial na segunda metade dos anos 1990 ofereceu oportunidade para um redesenho institucional, envolvendo não somente o Estado, mas sua relação com a sociedade civil. À medida que o Brasil começava a participar de diferentes processos de negociação, cuja abrangência compreendia questôes internas e fronteiriças, a negociação comercial atraiu a atenção não somente de diferentes organismos públicos - ausentes do cenário até então - mas também de um amplo conjunto de interesses domésticos privados (VEIGA, 2005, 6).

No entanto, como pontuou Carlos Faria (2008), as inovaçóes institucionais não se deram, necessariamente, sob a motivação democrática de um real compartilhamento social do poder decisório. Antes, há alegações, tanto da parte de representantes de governos subnacionais quanto de empresários, de que os negociadores do Itamaraty veem a eles, os novos stakeholders da PEB, como "massa de manobra" útil para fins de legitimação política. Também Veiga (2005) chamou a atenção para esse descompasso, pois, apesar das enormes mudanças ocorridas na relação entre o Estado e a sociedade civil no campo das negociaçōes comerciais, alguns elementos do padrão hegemônico de relacionamento ainda se mantiveram. Segundo o autor, "o diálogo muitas vezes se reduziu a 'prestação de informação' e somente em última instância representou 'tentativas genuínas de procurar uma contribuição mais ampla para a formulação de políticas’” (p. 50). Assim, a celebrada ampliação da participação e a inclusão de novos grupos no debate sobre política comercial no Brasil não se traduziram automaticamente num aumento proporcional no grau de transparência e na influência desses grupos na definição e implementação da política.

Tal perspectiva encontraria guarida na proposição de Zairo Cheibub (1985) de que, a partir da década de 1960, os diplomatas brasileiros do Itamaraty teriam deixado de se preocupar com aspectos organizacionais ou estilísticos para centrar o foco da sua atuação profissional na formulação da PEB. Isso teria colaborado para o fechamento da corporação em torno de si, bem como para a emergência de um senso comum entre os diplomatas de carreira de pertencimento à "elite burocrática” da nação (MOURA, 2007). Dentro desse novo paradigma, de que fala Cheibub, a democratização da sociedade brasileira veio figurar como um tipo de "ativo" institucional, ou seja, como insumo de uma imagem manipulada (pelos próprios diplomatas) do "Brasil para exportação", do "Brasil para inglês ver". A passagem a seguir, de autoria de Gelson Fonseca Jr. e Celso Lafer, formuladores proeminentes da PEB sob Cardoso, ilustra o afirmado:

Deve, portanto, ser uma preocupação prévia a qualquer planejamento de política externa uma aposta sobre que tendências vão prevalecer a curto e médio prazos no sistema internacional, se as centrípetas ou se as centrífugas, pois a aposta em uma ou outra direção pode sugerir, desde já, caminhos e opções diplomáticas. Na realidade, a questão se desdobra: é necessário avaliar de que 
maneira essas forças nos afetariam e, num segundo momento, saber de que maneira poderíamos influir para que a ordem mundial em gestação caminhasse em sentido favorável aos nossos interesses (LAFER \& FONSECA JR., 1997, 69, ênfases acrescentadas).

A PEB é pensada pelos autores como o produto de um planejamento estratégico realizado por especialistas, capazes de vislumbrar os rumos do sistema internacional e, a partir daí, perseguir os "nossos interesses". A política externa é concebida, evidentemente, como questão de Estado, não como agregação das forças sociais. Em artigo escrito para o jornal O Estado de S.Paulo, em dezembro de 2007, dez anos depois, Lafer tornaria a enunciar, de modo professoral, o seu entendimento sobre o processo da produção da política externa - embora lhe reconhecendo explicitamente a condição de política pública:

A política externa é uma política pública. Interessa a todos, pois trata da gestão dos interesses coletivos de uma nação no mundo. Cuida dos meios pelos quais um país se relaciona com os outros, lidando com os riscos dos conflitos, as oportunidades e os desafios econômicos e levando em conta os valores, ou seja, as afinidades e as discrepâncias políticas e culturais. (...) $\mathrm{Na}$ definição de metas de política externa é relevante identificar com sentido de prioridade o que um país realmente precisa obter no plano internacional para atender a suas necessidades internas, avaliando corretamente quais são, num determinado momento, suas possibilidades externas para alcançar segurança, desenvolvimento e bem-estar, prestígio e afirmar visōes do funcionamento do sistema internacional. No processo de gestão da política externa é preciso evitar dois riscos opostos: o de superestimar-se e o de subestimar-se (LAFER, 2007, ênfase acrescentada).

Outras tantas vezes, a democracia emergirá no discurso do Itamaraty sob Cardoso como um traço corroborador da modernização deste país, como um indicador de civilidade e de sofisticação político-institucional. Vide as reflexōes de Luiz Felipe Lampreia, o chanceler do presidente Cardoso entre 1995 e 2000, sobre o Brasil e a globalização:

Como resultante do enfrentamento $\mathrm{d}[\mathrm{e}]$ dois conjuntos de forças, as do progresso e as do atraso, [o Brasil é] um país que mostra uma notável vitalidade, mas cujo destino ainda depende de decisōes e de políticas em implantação ou em maturação e de uma vitória decisiva do novo sobre o velho. (...) Quer seu projeto nacional contemple uma vocação de hegemonia regional ou internacional (...), o Brasil sem dúvida está reunindo um bom potencial para dar um salto qualitativo tanto no seu desenvolvimento interno quanto na sua inserção internacional. Esse potencial é a resultante de diversos avanços que o país tem conseguido a partir da sua consolidação como uma democracia, uma sociedade majoritariamente urbana, uma economia industrial moderna e diversificada e com um grau crescente de interação com o mundo (...) 
O primeiro desdobramento [da globalização] é a acentuação da homogeneização da vida internacional em torno das duas forças centrais da democracia e da liberdade econômica. É evidente que continuará havendo exceções a essa tendência, mas o provável é que elas se confinem cada vez mais à periferia do sistema internacional (LAMPREIA, 1996, 41-43).

Em Lampreia, mais nitidamente, a noção de democracia como "ativo patrimonial" do Estado brasileiro - isto é, como elemento que distingue os países integrados à rede de relações internacionais modernas dos países atrasados ou periféricos - associa-se à pretensão autoral de um projeto nacional para a "hegemonia regional ou internacional". ${ }^{1}$ Porém, é na conferência intitulada $A$ política externa brasileira frente à democracia e à integração (1997), pronunciada na cidade de Buenos Aires, na Argentina, que se manifesta de forma mais inequívoca o seu pensamento acerca do duo democracia/PEB:

Estamos longe dos tempos em que os governos, isolados em torre de marfim do Estado, acreditavam-se capazes de conceber e implementar políticas impostas ou fazer acordos ou entendimentos exclusivamente oficiais, confiando na indiferença mais ou menos generalizada da sociedade civil. Atualmente, ao contrário da época áurea da diplomacia do 'balance of power' e das grandes alianças estratégicas, está comprovado que, sem a participação, sem o compromisso, sem o interesse e a compreensão daqueles agentes econômicos e sociais, de alguma maneira atingidos pelas decisões, as políticas de interação entre os Estados não prosperam. Resulta daí que o planejamento e a execução da política externa tornou-se um exercício democrático entre os governos e as sociedades. Em uma sociedade democrática, os governos não produzem interesses isolados, senão que os identificam e interpretam no diálogo e na interação constantes com a sociedade civil em geral e os diferentes setores em particular (LAMPREIA, 1999, 170-171).

$\mathrm{Na}$ fala do chanceler Lampreia fica sugerido o papel que caberia, contemporaneamente, ao Itamaraty: o de detector e "filtro" institucionalizado do interesse nacional - o qual seria equivalente, para efeito de análise, às demandas de setores organizados da sociedade civil. Mas é o governo que "identifica e interpreta", numa posição tutelar, as reivindicações feitas pelos diversos atores sociais e políticos. Também em Celso Lafer, sucessor imediato de Lampreia, chanceler entre 2001 e 2002, coincide a ideia de Brasil como "potência média de escala continental e relevância regional” (LAFER, 2004, 74). A realização desse projeto passaria por um cálculo de "razão de Estado", e não pela via da consulta popular ou pelo concurso de interesses dos stakeholders da PEB, como se atesta no trecho abaixo:

1 O conjunto de critérios que cacifam um eventual "salto qualitativo" do Brasil no mundo, em Lampreia (1996), inclui não apenas a consolidação democrática de um ângulo formal, mas a urbanização, a industrialização e a relativa extroversão do Estado/sociedade nos últimos tempos. Traz a inspiração das teorias da modernização, em voga nos anos 1960, tais como as de W. W. Rostow (1960) e Samuel Huntington (1968). 
Giovanni Botero, no seu livro de 1589 sobre a razão de estado, ao tratar conceitualmente de potências médias e de suas possibilidades de ação diplomática, aponta que elas teriam como característica não serem tão débeis e por isso tão expostas à violência como as pequenas, e simultaneamente por não provocarem, por sua grandeza, a inveja alheia, como as grandes. Além disso, porque os do meio participam dos extremos, têm, em princípio, a sensibilidade para exercitar a virtude aristotélica da equilibrada busca do meiotermo. O meio-termo aristotélico é uma das fórmulas de justiça e pode, por isso mesmo, dependendo das conjunturas diplomáticas, transformar-se num argumento de legitimidade, apto a alcançar uma abrangência generalizadora e interessar aos demais protagonistas da vida mundial (LAFER, 2004, 75-76, ênfase acrescentada).

Logo, é perceptível tanto em Luiz Felipe Lampreia, funcionário de carreira do MRE, quanto em Celso Lafer, professor da Universidade de São Paulo (USP) - os dois chefes do Itamaraty durante os oito anos da presidência de Fernando Henrique Cardoso (1995-2000 e 2001-2002, respectivamente) - um ânimo mais prescritivo e esquemático, ${ }^{2}$ que contrasta e pode até chocar-se com os apelos por maior abertura da formulação da PEB à participação da população (ou de setores desta).

\section{A "dialética do interesse nacional"}

Em Celso Amorim, o único chanceler de Luiz Inácio Lula da Silva desde 2003, as conexões discursivas e práticas entre democracia e PEB aparentam mais nuançadas e complexas. Em sua segunda passagem pela chefia do MRE, Amorim promoveu ajustes institucionais que foram desde a fórmula de acesso à carreira diplomática (o concurso público) até os mecanismos para ascensão hierárquica dentro dos quadros do Itamaraty. Inovações também aconteceram no que respeita à institucionalização de canais para interlocução com os novos stakeholders da PEB (encontros regulares com prefeitos e técnicos representantes das cidades, líderes de movimentos sociais, acadêmicos - Conferência Nacional sobre Política Externa e Política Internacional -, maior intercâmbio com diplomatas sul-americanos etc.). Notou-se a presença relativamente constante do chanceler nos meios de comunicação (jornais, revistas, televisão), o que fortaleceu a impressão de que havia uma correlação emergente entre a PEB e a opinião pública (FARIA, 2008). Em aditamento, ressalta-se a inédita importância assumida pela variável políticopartidária nessa gestão do MRE (LAFER, 2009; BARBOSA, 2010). ${ }^{3}$

\footnotetext{
2 Aqui eu me refiro, basicamente, à confiança que os chanceleres Lampreia e Lafer parecem depositar no cálculo racional do poder (entendido em termos tanto físicos quanto simbólicos) disperso na estrutura internacional como passo prévio a qualquer elaboração estratégica da política externa pelos tomadores de decisão do Estado devidamente preparados e institucionalmente autorizados para tal.

3 A esse respeito, cabe relembrar a intensa repercussão, nos meios de imprensa, da filiação do ministro Celso Amorim ao partido do presidente da República - o Partido dos Trabalhadores -, em setembro de 2009.
} 
Tais ajustes institucionais tiveram como objetivo - ou simplesmente como implicação prática - a promoção de mais choques de opinião sobre a PEB e de mais oportunidades para a participação do cidadão no seu processo decisório. Essa dificuldade foi enfrentada, de uma perspectiva teórica, pelo chanceler Amorim, em palestra proferida, em abril de 2007, no II Curso para Diplomatas Sul-Americanos. Segue transcrição de trecho da fala do chanceler:

Do mesmo jeito que há uma política social, uma política educacional, uma política econômica, há uma política externa. E, ao ser uma política externa, é também uma public policy, digamos assim. (...) É uma public policy e, por isso, espelha as atitudes e percepçôes dos governos. Naturalmente, essas percepções e essas atitudes não podem estar em contradição com aqueles princípios [constitucionais da PEB]. Mas elas são uma maneira de levar esses princípios à prática, de transformar esses princípios em diretrizes políticas.

E, um pouco mais adiante, no mesmo discurso:

Entre os princípios do relacionamento externo de um país e a política externa, há uma nuance. A segunda é uma maneira de executar os primeiros. E essa maneira de executar os primeiros varia, de governo para governo. Por isso é que todos os candidatos à presidência têm uma parte dos seus programas dedicada à política externa. (...) $\mathrm{O}$ que que é permanente? $\mathrm{O}$ respeito à independência dos Estados, a solução pacífica de controvérsias, os tratados internacionais, a inviolabilidade das fronteiras - isso são princípios da política externa brasileira. Mas como você conduz isso na prática são diretrizes políticas que cada governo tem (AMORIM, 2007).

A rigor, a dificuldade em questão é ontológica, pertence ao campo das definições primárias. Em poucas palavras: política externa é política de Estado ou de governo? As duas coisas, afirma categoricamente Amorim. As premissas constitucionais da PEB seriam o ponto de partida para uma formulação de política pública que variará conforme mudam as interpretações e as contingências do exercício de governo. O ponto de chegada - ou seja, a forma específica assumida pela PEB - dependerá, em última análise, do tipo de mandato que a população concedeu ao governante, das motivaçôes predominantes na sociedade. A pista sobre como isso se deva processar, em termos práticos, é dada por Amorim na sequência do referido discurso. In verbis:

A política externa é tradicionalmente vista como a defesa do interesse nacional. E qualquer coisa que não seja vista como a defesa do interesse nacional, será tida como mentira ou como ingenuidade. Todos nos lembramos da frase de [Theodore] Roosevelt: 'os EUA não têm amigos, têm interesses'. E isso é citado como defesa do interesse nacional. (...) Mas há algo que merece reflexão: eu acho que pode haver uma dialética entre o interesse nacional e a solidariedade. 
Nenhum país, nenhum presidente, nenhum ministro das relações exteriores pode deixar de defender o interesse nacional. Essa é a missão fundamental. Mas há necessariamente uma contradição entre o interesse nacional e uma certa busca da solidariedade? Eu acho que não. (...) A solidariedade corresponde ao nosso interesse nacional de longo prazo. Ela pode não corresponder ao interesse de curto prazo. Ela pode não corresponder ao interesse setorial de determinada parte da indústria ou da agricultura, ou de uma empresa brasileira. Mas ela corresponde ao interesse de longo prazo (idem, 2007, ênfase acrescentada).

O chanceler propõe abertamente uma síntese das contradições existentes entre a busca do autointeresse (individual ou setorial) e a necessidade, projetada para a nação, de uma espécie de "reciprocidade difusa" (RUGGIE, 1993) na região. Ou, ainda, uma via média entre o imediatismo/presentismo e o futuro escatológico. E, tratando especificamente da dinâmica democrática brasileira em face do empresariado:

É claro que todos nós vivemos em um ambiente político, e temos de responder aos grupos de interesse que existem no Brasil e em qualquer outro lugar. Isso quer dizer que nem sempre poderemos fazer tudo aquilo que consideramos justo. A gente faz - dentro daquilo que acha que é justo - aquilo que a gente pode. Há uma frase de [Blaise] Pascal muito interessante: 'não se podendo fazer com que o que é justo fosse forte, fez com que o que é forte fosse justo'. Adaptando um pouquinho: nós procuramos fazer a justiça dentro daquilo que é possível. Eu posso, em teoria, achar que poderia fazer mais. Mas também tenho os meus limites, ditados, evidentemente, por interesses que existem por aí. Isso não deve, porém, me levar para o campo oposto, e só olhar o interesse nacional brasileiro como interesse de curto prazo de uma empresa, de um setor industrial, de um setor econômico etc. (...). A combinação não é simples, não é óbvia, pode gerar críticas de um lado ou de outro, mas é verdadeira (AMORIM, 2007).

Depreende-se da leitura dos trechos acima que Amorim não tenciona uma síntese simétrica entre "autointeresse" e "solidariedade", e sim um equacionamento tendente ao segundo termo. ${ }^{4}$ Não se podendo conduzir inteiramente o processo, quer-se influenciá-lo o mais possível (conforme se lê: "nós procuramos fazer a justiça dentro daquilo que é possivel'). Curiosamente, em discurso de homenagem a Rui Barbosa, numa reflexão sobre o atual papel do Conselho de Segurança das Nações Unidas e a demanda (brasileira) pela expansão do seu número de membros, em novembro de 2007, Amorim volta a formular in abstracto sobre o tema, atingindo conclusão assemelhada:

4 Desde que se entenda por "solidariedade" a capacidade do MRE de determinar, republicanamente, aquilo que venha configurar "o interesse nacional de longo prazo" - o qual não deixaria de ser, em última análise, uma modalidade de autointeresse manifesta pelo ator institucional Itamaraty. 
Naturalmente é difícil conciliar - e aqui quero chamar atenção para um paradoxo que é preciso enfrentar com lucidez... Naturalmente é difícil conciliar o ideal democrático em sua forma mais pura, que inspirava o pensamento de Rui Barbosa, e a necessidade de um órgão com decisão rápida e eficaz em temas que exigem soluçôes muitas vezes em caráter de urgência, como são os da paz e da segurança internacionais. Não creio, honestamente, que haja respostas absolutas ou irrefutáveis para esta contradição intrínseca. O que podemos almejar no atual estágio da relação entre os Estados é um sistema que busque equilibrar da melhor forma critérios de representatividade e de eficácia (AMORIM, 2008, 22-23).

O que torna a fala de Amorim digna de nota é justamente o seu esforço de distanciamento em relação ao tema, esforço para produzir análise supostamente desinteressada nos resultados do processo em tela. É bem sabido que, na questão da reforma do Conselho de Segurança da ONU, o "lado" ocupado pelo Itamaraty é o das reivindicaçōes por maior democratização do acesso aos fóruns decisórios da política internacional, o que viria a contemplar o Brasil. Evidentemente, portanto, não se espera do chanceler brasileiro postura outra que a defesa direta e sem ressalvas do "interesse nacional". No entanto, coerentemente com o conceito esboçado de "dialética do interesse nacional", Amorim hesitará, acusando a própria incapacidade de prover "respostas absolutas ou irrefutáveis para esta contradição intrínseca".

\section{O fim do "consenso de Tancredo"?}

Numa série de artigos conjunturais, produzidos para o jornal Folha de S.Paulo entre dezembro de 2001 e junho de 2005, o embaixador Rubens Ricupero proporá, com diferentes fraseados, a seguinte questão (RICUPERO, 2001; 2002; 2005): o que terá restado do "consenso de Tancredo"?

O consenso a que aludia Ricupero era a tendência, diagnosticada pelo então candidato à presidência da República, Tancredo Neves, de concordância entre todas as correntes democráticas da política brasileira, no ano de 1984, quanto às direções da política externa brasileira conduzida pelo Itamaraty. A conclusão a que chega o embaixador é de que "da quase unanimidade (...) sobre a estratégia externa, pouca coisa sobreviveu” (RICUPERO, 2001). A crise da dívida fora responsável pela deslegitimação daquela abordagem pragmática da política externa que se justificava com o argumento de um necessário "crescimento rápido da economia". Ainda, a doutrina autonomista de defesa nacional teria tombado em face da afirmação da democracia formal, nos anos 1980.

A análise de Ricupero suscita uma questão que é academicamente relevante: a transformação por que teria passado a PEB "conduzida pelo Itamaraty" de um paradigma do "silêncio respeitoso" (ou de um consenso com baixo grau de participação política da sociedade) para outro de intensa (e, por vezes, acalorada) disputa entre stakeholders pela definição da agenda internacional do Estado 
brasileiro. ${ }^{5}$ Com um quê de analista e outro de profeta, Gelson Fonseca Jr. observou, nos idos de 1998:

Minha primeira observação diz respeito ao próprio interesse que os processos diplomáticos despertam na cidadania. Em regra, o país é introvertido. São de tal ordem os problemas internos (...) que 'tradicionalmente' a diplomacia não tem sido objeto de um debate 'organizado' na imprensa, no Parlamento, nos meios de comunicação de massa. A situação tende, contudo, a se alterar. Amplia-se a consciência de que qualquer projeto nacional é afetado pelas condiçôes internacionais, pelas opçōes políticas que fazemos. O fenômeno qualifica não só aqueles temas que modificam interesses concretos, (...) mas também outros, mais precipuamente políticos (FONSECA JR., 1998, 355-356, ênfase acrescentada).

Essa alteração avistada no modus operandi do sistema de política exterior do Brasil é justamente o fenômeno a que o trabalho se tem dedicado. Alegadamente, no quarto de século que se segue desde a redemocratização formal do Brasil, é possível notar-se, conforme alega o diplomata Paulo Roberto de Almeida (2003; 2007), a influência do Partido dos Trabalhadores (PT) - do presidente Lula da Silva - na configuração da "ideologia" da PEB. A crítica ao modelo de gestão corrente vem dos que ponderam tratar-se de uma ruptura com a tradição apartidária de mais de um século do Itamaraty. ${ }^{6} \mathrm{O}$ embaixador aposentado Rubens Barbosa acrescenta criticamente, mirando o caso de Marco Aurélio Garcia, atual assessor especial para assuntos internacionais da Presidência da República e ex-presidente nacional do PT, que a estratégia brasileira de aproximação dos países da América Latina pelos canais partidários é de todo equivocada, não por ser uma política de Estado, mas sim de governo (DIEGUEZ, 2009). Celso Lafer (2009) também declara, sobre a suposta partidarização da $\mathrm{PEB}$, que a filiação do chanceler Celso Amorim ao Partido dos Trabalhadores, no ano de 2009, é mais um forte indício dessa ruptura. ${ }^{7}$

Se possível fosse identificar um marco zero do processo que aqui chamamos de "politização ruidosa" da $\mathrm{PEB},{ }^{8}$ ele seria a publicação da entrevista concedida por Roberto Abdenur, ex-embaixador do Brasil nos Estados Unidos ${ }^{9}$ e ex-secretáriogeral do Itamaraty (durante a primeira passagem de Amorim pela chefia do MRE),

5 Para uma visão compatível com a de Ricupero, embora distinta, cf. Veiga (2010).

6 A propósito: um exercício rico e proveitoso é consultar a seção dedicada à política externa no programa de governo do candidato Luiz Inácio Lula da Silva. Há boa correspondência entre as linhas de ação preconizadas pelo PT, ainda em 2002, e a PEB que se materializaria na sequência.

7 Cabe aqui uma nota de esclarecimento. Penso que há pelo menos duas maneiras de compreender a expressão "partidarização da política externa". No sentido pretendido pelos autores listados nesse parágrafo, ela aproxima-se de "ideologização", isto é, do balizamento da política externa por critérios exclusivamente partidários, facciosistas. Num sentido alternativo, trata-se de reconhecer, por meio de metodologia própria, a influência do partido político do chefe de governo - no Brasil, o presidente da República - na conformação do conteúdo de uma política pública específica (nomeadamente, a política externa).

8 Isto é, a escalada verbal e a explicitação das tensōes políticas e ideológicas existentes, desde há muito, no interior da corporação diplomática brasileira.

9 Coincidentemente, os embaixadores Rubens Ricupero e Rubens Barbosa também ocuparam previamente esse posto. 
à revista Veja, em fevereiro de 2007. Após adjetivar a PEB de Amorim/Lula de "ideológica" e "antiamericanista", além de denunciar a "intolerância à pluralidade de opiniáo" no seio do Itamaraty, Abdenur ajudou a promover o desencadeamento de tensões políticas que se arrastam até hoje. O recentemente finado ex-chanceler Mário Gibson Barboza escreveu, em sequência à entrevista de Abdenur, uma coleção de artigos em que alvejava a condução do MRE feita por Amorim. Dentre outros aspectos, ele acusava abertamente estar havendo:

Politização dos diplomatas, para que possam obter promoção ou os melhores postos no exterior. Por 'politização' entenda-se entusiástica adesão política ao petismo e ao atual Governo; absurda e desnecessária criação de novos 400 cargos de diplomatas, quando éramos pouco mais de 900; leitura obrigatória de textos históricos e/ou diplomáticos e subsequente e vexatória 'tomada de lição', visando à formação de uma ideologia unificada (BARBOZA, 2008, 173).

Em carta aberta ao chanceler Celso Amorim, publicada no Jornal do Brasil, em 16 de dezembro de 2007, outro embaixador aposentado, Márcio Dias, escreveu:

Como um grande número de colegas, acompanho com desaprovação mas em silêncio a maneira como você e Samuel [Pinheiro Guimarães] vêm conduzindo o Itamaraty. Hierarquizados como somos, ainda acreditamos no velho bordão de que quem fala pela Casa é o seu Chefe. Assim, ao nos darmos conta, logo no início do Governo Lula, de quem iria dirigir a Casa nos próximos anos, muitos, como eu, preferimos aposentar-nos a seguir na ativa sob uma direção de que fatalmente discordaríamos. A propósito, nunca em momento algum do Itamaraty, houve tantos Embaixadores aposentados voluntária e precocemente. (...) Com o Governo do PT e conhecendo a sua 'flexibilidade', mais o viés ideológico do Samuel, vários, como eu, previmos o que estaria por acontecer e, com o espírito de disciplina da carreira, preferimos dela nos afastar, por estimarmos que viríamos a discordar frontalmente da maneira pela qual a Casa seria conduzida (DIAS, 2007, p. A11).

Seria equivocado, no entanto, imaginar que o ministro Celso Amorim e seus colaboradores mais próximos tenham permanecido na defensiva por todo o período de governo Lula. Cabe recordar a animosidade prévia entre Samuel Pinheiro Guimarães (então diretor do Ipri/MRE), acerbo crítico do projeto da Área de Livre Comércio das Américas (Alca), e Celso Lafer, ministro das Relaçōes Exteriores do governo Cardoso entre 2001 e 2002. A condenação pública que Guimarães (2001) fizera ao projeto da Alca lhe teria rendido punição política, traduzida na sua remoção do Ipri e no que ficou conhecido como "a lei da mordaça"10 (a circular postal 87/96, segundo a qual "todos os funcionários do Serviço Exterior Brasileiro [deveriam pedir] autorização para manifestações públicas sobre matéria

10 Cf. "Itamaraty baixa 'lei da mordaçà para os diplomatas brasileiros", Folha de S.Paulo, 17 de fevereiro de 2001. 
relacionada à formulação e à execução da política exterior do Brasil”). Tão logo nomeado ministro, em 2003, Amorim guindou Guimarães à posição de secretáriogeral do Itamaraty - em que permaneceu até a sua aposentadoria, em 2009. Outra controvérsia dos tempos do governo Fernando Henrique Cardoso envolveu o embaixador José Maurício Bustani. Quando presidia a Organização para a Proibição de Armas Químicas (Opaq), em 2002, Bustani foi vítima de campanha políticodiplomática estadunidense, que culminou com a sua destituição do cargo. À época, alegou-se que teria faltado ao governo brasileiro empenho para mantê-lo no posto. Sintomaticamente, em 2003, Bustani foi indicado para a embaixada brasileira em Londres, tida como uma das mais prestigiosas. ${ }^{11}$

A polêmica sobre a "politização" do Ministério das Relações Exteriores encontra eco também entre os acadêmicos, jornalistas e intelectuais. Conforme propôs Paulo Roberto de Almeida (2006), parece razoável dividir os comentaristas entre opositores ou "independentes" (Demétrio Magnoli, Marco Antonio Villa, Jorge Zaverucha, Marcelo de Paiva Abreu, José Augusto Guilhon Albuquerque, Rolf Kuntz, Ali Kamel e Augusto Nunes, dentre outros) e apoiadores ou "simpatizantes" (José Luís Fiori, Maria da Conceição Tavares, Ricardo Seitenfus, Paulo Nogueira Batista Jr., Luiz Alberto Moniz Bandeira, José Flávio Sombra Saraiva, Paulo Fagundes Vizentini, Luiz Felipe de Alencastro e Amado Luiz Cervo, dentre outros) da gestão da PEB que ora se desenrola. ${ }^{12}$

Nos órgãos da grande imprensa nacional, a porta-voz mais agressiva da contestação tem sido a revista $V e j a$, que já dedicou algumas de suas capas ao tema da PEB nos últimos anos (vide "O PT deixou o Brasil mais burro?", de 26 de janeiro de 2005, em alusão à retirada do caráter eliminatório da prova de inglês no concurso de admissão à carreira diplomática; e "Imperialismo megalonanico", de 30 de setembro de 2009, sobre a crise de Honduras), além de inúmeras matérias críticas à atual condução do MRE. A ela contrapõe-se a revista Carta Capital, frequentemente elogiosa dos rumos assumidos pela PEB de Lula/Amorim, o que também se manifestou em algumas de suas capas ("Quem tem medo da política externa?", de 28 de fevereiro de 2007, em referência às bases da política exterior de Amorim; ou "Personagem do mundo", de 2 de dezembro de 2009, sobre a diplomacia presidencial de Lula) e reportagens veiculadas.

11 “Após sua destituição, Bustani ocupou provisoriamente o posto de cônsul-geral do Brasil em Londres, mas acabou afastado. Chocou-se com o ex-chanceler Celso Lafer, ao acusá-lo repetidas vezes de não ter movido uma palha para impedir o impasse da Opaq. Ao lado do atual embaixador do Brasil na Áustria, Roberto Abdenur, o então embaixador no Reino Unido e atual chanceler, Celso Amorim, foi um dos poucos a manifestar diretamente a Lafer seu apoio a Bustani, de quem igualmente é amigo de longa data". Cf. "Bustani aguarda parecer para assumir embaixada em Londres", O Estado de S.Paulo, 12 de janeiro de 2003.

12 José Luís Fiori (2009) profere sobre o atual estado do debate a respeito da política externa brasileira: "A cada dia aumenta o número de diplomatas aposentados, iniciantes políticos e analistas que batem cabeça nos jornais e rádios, sem conseguir acertar o passo, nem definir uma posição comum sobre qualquer dos temas que compõem a atual agenda externa do país. Pode ser o caso do golpe militar em Honduras, ou da entrada da Venezuela no Mercosul; da posição do Brasil na reunião de Copenhague ou na Rodada de Doha; da recente visita do presidente do Irã, ou do acordo militar com a França; das relaçōes com os Estados Unidos ou da criação e do futuro da Unasul”. 
No que tange, finalmente, aos três grandes jornais impressos do país, Folha de S.Paulo, O Estado de S. Paulo e O Globo, pouca variação há. Seus editoriais costumam criticar, de forma contumaz, aspectos diversos da política externa do corrente governo $^{13}$ - o que ilustra, definitivamente, o argumento de que temas internacionais se têm tornado crescentemente importantes para a opinião pública brasileira nestes dias.

\section{Considerações finais}

A rigor, no curto intervalo de apenas uma geração, é provável que se tenha passado com a PEB aquilo que o francês Bertrand Badie chamou de "a intrusão da sociedade". Isso porque, no referente a temas de política internacional, os povos, os grupos sociais, os indivíduos em geral são tratados, tradicionalmente, como intrusos. Badie (2008) aponta que, embora tenham ingressado na arena internacional sem ser convidados, esses "intrusos" dispōem de legitimidade e de recursos de poder tais que dificilmente deixarão de ser notados pelos tomadores de decisão estatais. O custo político de ignorá-los é muito alto. À medida que um espaço público internacional se vai consolidando, a diplomacia passa a ser perturbada pelos agentes da sociedade - mesmo quando os atores sociais não se dão conta, ao fazerem demandas que se anunciam como domésticas, mas que remetem a processos de negociação travados para além das fronteiras nacionais.

Em poucas palavras, portanto, deu-se aparentemente que o "consenso de Tancredo" teve de se avir com a "sociedade intrusiva" do Brasil contemporâneo. O saldo da operação é uma política externa não monolítica, não unânime, repleta de dissensos internos quanto a suas ênfases e métodos, resultante da agregação assimétrica de interesses de atores sociais e institucionais bastante diversos entre si.

\section{Referências bibliográficas}

Fonte primária:

MINISTÉRIO DAS RELAÇÕES EXTERIORES (MRE). Reflexōes sobre a Politica Externa Brasileira (documento de trabalho, circulação restrita). Brasília: FUNAG; IPRI; SubsecretariaGeral de Planejamento Econômico e Político, 1993.

13 Cf. os seguintes editoriais: "Liçôes de Honduras" (Folha de S.Paulo, 29 de janeiro de 2010); "Um passo atrás" (Folha de S.Paulo, 29 de setembro de 2009); "Mais uma do Itamaraty" (Folha de S.Paulo, 21 de maio de 2009); "Ventos de Teeră" (O Globo, 29 de dezembro de 2009); "Argumento falso" (O Globo, 4 de novembro de 2009); "Mais um erro" (O Globo, 8 de maio de 2009); "Erros da política externa e comércio" (O Estado de S.Paulo, 6 de janeiro de 2009); "Uma diplomacia de erros" (O Estado de S.Paulo, 4 de janeiro de 2009); "Diplomacia desastrada" (O Estado de S.Paulo, 7 de dezembro de 2008); "Diplomacia infeliz" (O Estado de S.Paulo, 22 de julho de 2008); entre tantos outros de conteúdo crítico à gestão da política externa de Lula e Amorim. 
Fontes secundárias:

ALMEIDA, Paulo Roberto de. A política internacional do Partido dos Trabalhadores: da fundação do partido à diplomacia do governo Lula, Revista de Sociologia e Política, n. 20, jun 2003, p. 87-102.

Uma nova 'arquitetura' diplomática? Interpretações divergentes sobre a política externa do governo Lula (2003-2006), Revista Brasileira de Politica Internacional, 2006, v. 49, n. 1, p. 95-116.

A diplomacia do governo Lula em seu primeiro mandato (2003-2006): um balanço e algumas perspectivas, Carta Internacional, 2007, v. 2, p. 3-10.

AMORIM, Celso. Politica Externa. Democracia. Desenvolvimento. Brasília: Fundação Alexandre de Gusmão, 1995.

. A Nova Politica Externa Independente. Transcrição de palestra concedida por ocasião do II Curso para Diplomatas Sul-Americanos. Rio de Janeiro, 2 a 20 de abril de 2007.

A diplomacia multilateral do Brasil - um tributo a Rui Barbosa. Brasília: Funag, 2008.

BADIE, Bertrand. Le diplomate et l'intrus. Paris: Fayard, 2008.

BARBOSA, Rubens. A política externa do governo Lula, O Estado de S.Paulo, 23 de fevereiro de 2010, p. A2.

BARBOZA, Mario Gibson. O Brasil e o eixo do Pacífico, Ideias em Destaque, n. 27, mai-jun 2008, p. 170-173.

CASARÕES, Guilherme. A economia política do governo Collor: discutindo a viabilidade de governos minoritários sob o presidencialismo de coalizão. Dissertação de mestrado - Faculdade de Filosofia, Letras e Ciências Humanas, Departamento de Ciência Política, Universidade de São Paulo. São Paulo, 2008, 138 p.

CASTORIADIS, Cornelius. Figuras do Pensável. Rio de Janeiro: Civilização Brasileira, 2004.

CHEIBUB, Zairo. Diplomacia e Construção Institucional: O Itamaraty em uma Perspectiva Histórica, Dados, 1985, v. 28, n. 1, p. 113-131.

DIAS, Marcio. Carta aberta ao chanceler Celso Amorim, Jornal do Brasil, 16 de dezembro de 2007, p. A11.

DIEGUEZ, Consuelo. O formulador emotivo, Piauí, março de 2009, n. 30.

FARIA, Carlos Aurélio Pimenta de. Opinião pública e política externa: insulamento, politização e reforma na produção da política exterior do Brasil, Revista Brasileira de Política Internacional, 2008, vol. 51, n. 2, p. 80-97.

FIORI, José Luís. 2009. O debate da política externa: os conservadores. Publicado em: [http://www.cartamaior.com.br/templates/colunaMostrar.cfm?coluna_id=4483\&boletim_ id=622\&componente_id=10414]. Acessado em: 11 de março de 2010.

FONSECA JR., Gelson. A legitimidade e outras questôes internacionais. São Paulo: Paz e Terra, 1998.

GUIMARÃES, Samuel Pinheiro. 2001. A Alca e o fim do Mercosul. Publicado em: [http:// www.buscalegis.ufsc.br/revistas/index.php/buscalegis/article/view/21583/21147]. Acessado em: 11 de dezembro de 2010 .

HUNTINGTON, Samuel. Political Order in Changing Societies. New Haven: Yale University Press, 1968. 
LAFER, Celso. A identidade internacional do Brasil e a politica externa brasileira. São Paulo: Ed. Perspectiva, 2004. 2007, p. A2.

Novas variações sobre a política externa, O Estado de S.Paulo, 16 de dezembro de Partidarização da política externa, O Estado de S.Paulo, 20 de dezembro de 2009, p. A2. et al. Entrevista com Celso Lafer, Revista Estudos Históricos, 1993, Vol. 2, No 12.

e Fonseca Jr., Gelson. Questôes para a Diplomacia no Contexto Internacional das Polaridades Indefinidas (Notas Analíticas e Algumas Sugestôes). In: FONSECA JR., G. e CASTRO, S. (org.). Temas de Política Externa Brasileira II. Brasília: FUNAG; São Paulo: Paz e Terra, vol. 1, 1997.

LAMPREIA, Luiz Felipe. O Brasil e o mundo no século XXI: uma visão do Itamaraty, Política Externa, v. 5, n. 3, dez. 1996.

1999.

Diplomacia brasileira. Palavras, contextos e razôes. Rio de Janeiro: Lacerda Editores,

MOURA, Cristina Patriota. O Instituto Rio Branco e a Diplomacia Brasileira. Rio de Janeiro: FGV Editora, 2007.

O’DONNELL, Guillermo. 2004. Notas sobre la Democracia en América Latina, Informe La Democracia en América Latina (Anexo 2: El Debate Conceptual sobre la Democracia en América Latina). Publicado em: [http://democracia.undp.org]. Acessado em: 28 de julho de 2006.

PENNA FILHO, Pio. A pesquisa histórica no Itamaraty, Revista Brasileira de Política Internacional, 1999, Vol. 42, No 2, p. 117-144.

RICUPERO, Rubens. O que restou do consenso de Tancredo?, Folha de S.Paulo, 30 de janeiro de 2001.

A terceira perna da mesa, Folha de S.Paulo, 13 de janeiro de 2002.

Fim do consenso?, Folha de S.Paulo, 12 de junho de 2005.

ROSTOW, W. W. The Stages of Economic Growth, a Non-Communist Manifesto. Cambridge: Cambridge University Press, 1960.

RUGGIE, John (ed.). Multilateralism matters. New York: Columbia University Press, 1993.

SEIXAS CORRÊA, Luiz Felipe de (org.). O Brasil nas Naçôes Unidas. Brasília: Funag, 2007.

VEIGA, Pedro da Mota. 2005. Formulação de políticas comerciais no Brasil: a mudança do padrão de relacionamento entre o Estado e a sociedade civil. Publicado em: [http://www. cindesbrasil.org/index.php?option=com_docman\&task=doc_details\&gid=371\&Itemid=47]. Acessado em: 9 de março de 2010.

A política externa sob Lula - o fim do consenso, O Estado de S.Paulo, 16 de agosto de 2010 , p. B2.

Recebido em 22 de julho de 2010 Aprovado em 11 de janeiro de 2011 


\section{Resumo}

O artigo busca examinar, desde a realização da primeira eleição direta para a Presidência da República após a redemocratização (1989) até o último ano do segundo termo presidencial de Lula da Silva (2010), a progressiva politização da Política Externa Brasileira (PEB), sob a égide das instituições democráticas no plano doméstico e a renovada influência jogada por atores e processos internacionais.

Palavras-chave: democracia; política externa; Brasil.

\section{Abstract}

This article examines the progressive politicization of Brazilian Foreign Policy since the first direct presidential election held in Brazil after the redemocratization (1989) until the last year in office of President Lula da Silva's second term (2010), under the aegis of domestic democratic institutions and the renewed influence played by international actors and processes.

Keywords: democracy; foreign policy; Brazil. 